\title{
Risk factors of life style diseases among adults in Kozhikode, Kerala
}

\author{
Anirudh V. Mutalik', Anant T. Pawar ${ }^{2, *}$ \\ ${ }^{\mathbf{1}}$ Assistant Professor, ${ }^{2}$ Professor and HOD, Dept. of Community Medicine, KMCT Medical College, Kerala, India
}

*Corresponding Author:

Email: dr.anantp@gmail.com

\begin{abstract}
Introduction: Life style diseases refer to diseases that are caused mainly due to the unhealthy behavior and choices people make in their life. Economic growth, modernization, urbanization and socialization have changed the life style of Indian families. Most of the life style diseases share common preventable risk factors such as tobacco, high alcohol consumption, anxiety, sedentary life style and obesity. All these risk factors are modifiable and early identification and management of risk factors can help to prevent and control non-communicable diseases.

Objectives: To screen the population for risk factors of chronic non-communicable diseases

Materials and Methods: A community based cross sectional study was conducted. A house to house survey was conducted. All individuals above 20 years of age; who gave informed consent were included in the study. Detailed information regarding age, sex, educational status, marital status, occupation and occupational activity, religion, dietary habits, personal habits and addiction, family history of diseases and other relevant information etc. was obtained using predesigned questionnaire. Modified B.G. Prasad classification updated for January 2017 was used for socioeconomic classification. Anthropometric measurements such and Blood pressure were measured using standard techniques. Data was entered in MS excel and analyzed using SPSS 16.

Results: Most of the people (43) in the study population were less than 40 years of age. Slight Female preponderance was observed in the study. $66 \%$ of subjects belonged to socioeconomic status class II. Only $28 \%$ of the study population exercised regularly. Percentage of overweight and obese among study population was $31 \%$. Among 46 males from study population 26 had one or other addiction. 20 subjects reported hypertension, 16 were diabetic and 2 were CAD patients.
\end{abstract}

Keywords: Lifestyle diseases, Screening, Diabetes Mellitus, Hypertension.

\section{Introduction}

Life style diseases refer to diseases that are caused mainly due to the unhealthy behavior and choices people make in their life. They are associated with the way a person or group of people live. The onset of the life style diseases is insidious, they take years to develop and once encountered do not lend themselves easily to cure. In past few decades we have witnessed a rapid transformation in the lifestyle of Indians, particularly those living in urban India. Economic growth, modernization, urbanization and socialization have changed the life style of Indian families. ${ }^{1}$

The main life style diseases are cardiovascular diseases, stroke, diabetes, cancer, COPD, depression, hypertension, cirrhosis. Cardiovascular diseases, cancer and type- 2 diabetes mellitus accounts for $53 \%$ of all deaths and $44 \%$ of disability adjusted life years lost in India. ${ }^{2}$ Most of the life style diseases share common preventable risk factors such as tobacco, high alcohol consumption, anxiety, sedentary life style and obesity. Clustering of these risk factors significantly increases the risk of morbidity and mortality. All these risk factors are modifiable and early identification and management of risk factors can help to prevent and control non-communicable diseases. ${ }^{3}$ We should adopt a healthy life style in the families from an early age to combat these diseases with a proper balanced diet, regular exercise and physical activity, stress control and by giving due respect to biological clock.

Kerala is the Indian state which is going through the epidemiological transition; it has the lowest prevalence of communicable diseases and has the highest prevalence of the non-communicable diseases (NCD). ${ }^{4}$ Kerala is the diabetic capital for India and even reports high cardiovascular mortality. ${ }^{5,6}$ Kerala also has the highest prevalence of overweight and obese women in the reproductive age group in India. ${ }^{7}$ Huge development has occurred in the study area in last few years and is going on. Overall improvement in Socioeconomic status of people in area has resulted in changes in life style of people; increasing risk of life style diseases. So it was decided to study risk factors of lifestyle diseases in the population.

\section{Objectives}

1. To screen the population for risk factors of chronic non-communicable diseases

2. To assess relationship between lifestyle and presence of chronic non-communicable diseases?

\section{Materials and Methods}

A community based cross sectional study was conducted in the field practice area of urban health centre run by Community Medicine Department of KMCT Medical College in Mukkam Municipality. One ward was randomly selected for study. A house to house survey was conducted by group of trained eleven students during Community Medicine posting. All individuals above 20 years of age; who gave informed consent were included in the study. Seriously ill patients, people who refused to give consent and those who were not able to respond to questionnaire were 
excluded from the study. A total of 100 individuals were selected by simple random sampling technique and formed study population.

Detailed information regarding age, sex, educational status, marital status, occupation and occupational activity, religion, dietary habits, personal habits and addiction, family history of diseases and other relevant information etc. was obtained using predesigned questionnaire. Modified B.G. Prasad classification updated for January 2017 was used for socioeconomic classification.

Anthropometric measurements such as weight and height were measured using standard techniques. Blood pressure was measured by mercury sphygmomanometer, pulse obliteration and auscultation method in sitting position. Two separate reading at an interval of minimum 10 minutes were taken and average was calculated. The hypertension was defined as systolic BP equal to or more than $140 \mathrm{~mm}$ of $\mathrm{Hg}$ or diastolic BP equal to or more than $90 \mathrm{~mm}$ of $\mathrm{Hg}$. Individuals who were known cases of diabetes, hypertension, CVDs and were on treatment were considered as diseased. Data was entered in MS excel and analyzed using SPSS 16.

\section{Results}

This study was carried out among 100 subjects selected by simple random sampling technique from study area. Some socio-demographic characteristics of study population are shown in table 1 .

Most of the people (43) in the study population were less than 40 years of age; 21 subjects were above 60 years of age and 9 of them were above 70 years. Slight Female preponderance was observed in the study with 54 females for 46 males. 100\% Literacy was observed in study population with 21 graduates and 5 postgraduates. Maximum number of subjects belonged to socioeconomic status class II $(66 \%)$ and class III (23).

Table 2 shows lifestyle of study population. Only $28 \%$ of the study population exercised regularly but $56 \%$ subjects preferred walking to reach their nearby surroundings. Percentage of overweight and obese among study population was $31 \%$ (BMI>25).

Family history of Diabetes and hypertension was reported by $37 \%$ and $47 \%$ population respectively. Percentage of pure vegetarians in study population was just $12 \%$. Among 46 males from study population 26 had one or other addiction. 11 were smokers 16 were alcoholics and 4 were betel chewers. None of the women was tobacco user or alcoholic. 20 subjects reported hypertension, 16 were diabetic and 2 were CAD patients.
Table 1: Socio demographic profile of study population

\begin{tabular}{|l|c|}
\hline Characteristics & \\
\hline Gender & 46 \\
\hline Male & 54 \\
\hline Female & \\
\hline & \\
\hline Educational status & 24 \\
\hline Primary & 49 \\
\hline High school and Higher Secondary & 26 \\
\hline Graduation and above & \\
\hline & \\
\hline Socioeconomic status & \\
\hline Upper- I & 8 \\
\hline Upper middle- II & 66 \\
\hline Lower middle- III & 23 \\
\hline Upper lower- IV & 4 \\
\hline Lower- V & \\
\hline
\end{tabular}

Table 2: Risk factors of lifestyle diseases in the study population

\begin{tabular}{|l|c|}
\hline Food pattern & \\
\hline Vegetarian & 12 \\
\hline Non-Vegetarian & 88 \\
\hline & \\
\hline Exercise pattern & 28 \\
\hline Regular & 72 \\
\hline Irregular or no exercise & \\
\hline & \\
\hline Body Mass Index & 7 \\
\hline$<18.5$ & 62 \\
\hline 18.5 -25 & 31 \\
\hline$>25$ & \\
\hline & \\
\hline Family history & 47 \\
\hline Hypertension & 37 \\
\hline Diabetes & \\
\hline & \\
\hline Addictions & 11 \\
\hline Smoking & 4 \\
\hline Chewing & 16 \\
\hline Alcohol & \\
\hline & \\
\hline Morbidities & 20 \\
\hline Hypertension & 16 \\
\hline Diabetes & 2 \\
\hline CAD & \\
\hline
\end{tabular}

\section{Discussion}

This study was conducted in the population; which is in transition from semi-urban to urban area and this transition is most likely to affect their lifestyle. The present study has revealed a substantially high rate of prevalence of some of the behavioural risk factors in the community, especially the habit of smoking and alcohol consumption among men. In the present study 
overall prevalence of smoking among males was $23.9 \%$ while that of alcohol among males was $34.8 \%$. Almost similar findings are reported in study done in Nagpur, Maharashtra by SD Bhardwaj. ${ }^{8}$ In his study prevalence of smoking was $20.5 \%$ and that of alcohol consumption was $37.7 \%$. In his study, also none of the women was either smoker or alcoholic. In study done by Thankappan ${ }^{4}$ in Kerala, prevalence of smoking was $28.0 \%$ almost like our findings but prevalence of alcohol consumption was $15.4 \%$ which is much less compared to findings of present study. Another study done in Kerala by TN Sugathan ${ }^{9}$ however reported $41 \%$ prevalence of alcohol consumption in his study which is almost similar to our study.

In the present study $20 \%$ subjects were hypertensive, 16 were diabetic and 2 had cardiovascular diseases. 39\% of our population was overweight and 8 among them were obese. Almost same prevalence of hypertension $19.8 \%$ was observed by author in his previous study in same area. ${ }^{10}$ Thankappan in his study done in Kerala reported overall prevalence of hypertension and diabetes $28.8 \%$ and $14.8 \%$ respectively. ${ }^{4} \mathrm{He}$ also reported abdominal obesity among $33.9 \%$ of population. Sebastian reported 32.3\% hypertension in his study. ${ }^{11}$

In the present study, most of the population $88 \%$ was nonvegetarian. Finding of our study are totally different from studies done in other parts of India ${ }^{12,13}$ but dietary pattern of Kerala is unique even Wilson $\mathrm{C}$ in his study in Kerala reported that, 82.8 per cent of the people consume at least one non-vegetarian dish a day. ${ }^{14}$

\section{Conclusion}

High prevalence of various behavioural risk factors was observed in this study. This indicates definite possibility of high morbidity burden occurring in near future. Public health remedial measures will therefore be urgently needed in order to minimize future morbidity burden. Regarding smoking and alcohol consumption, a strict public policy in restricting its use and its distribution may be considered.

\section{References}

1. Pappachan M. J. Increasing prevalence of lifestyle diseases: high time for action. The Indian Journal of Medical Research. 2011;134(2):143-145.

2. Reddy KS, Shah B, Varghese C, Ramadoss A. Responding to the threat of chronic diseases in India. Lancet 2005;366:1744-9.

3. Park K. Epidemiology of Non communicable diseases and conditions. In: K Park, Park's textbook of Preventive and Social Medicine $23^{\text {rd }}$ edn, Jabalpur. M/S Banarsidas Bhanot Publishers; 2015.

4. Thankappan KR, Shah B, Mathur P, Sarma PS, Srinivas G, Mini GK, et al. Risk factor profile for chronic noncommunicable diseases: results of a community-based study in Kerala, India. Indian J Med Res. 2010;131:5363. [PubMed: 20167974]
5. Mohan V, Sandeep S, Deepa R, Shah B, Varghese C. Epidemiology of type 2 diabetes: Indian scenario. Indian $J$ Med Res. 2007;125:217-30. [PubMed: 17496352]

6. Soman CR, Kutty VR, Safraj S, Vijayakumar K, Rajmohan $\mathrm{K}$, Ajayan K. All-cause mortality and cardiovascular mortality in Kerala State of India: Results from a 5-year follow-up of 161942 rural community dwelling adults. Asia Pac J Public Health. 2010;23:896-903. [PubMed: 20460280]

7. National Family Health Survey 3 (NFHS-3) India, Kerala report 2005-2006. Mumbai: [accessed on October 23, 2011]. International institute for population studies (IIPS) and ORC macro 2006. Available

from: http://hetv.org/india/nfhs/nfhs3/NFHS-3-Kerala-statereport.pdf.

8. SD Bhardwaj, MK Shewte, PR Bhatkule, JR Khadse. Prevalence of risk factors for non-communicable disease in a rural area of Nagpur district, Maharashtra - A WHO STEP wise approach. Int J Biol Med Res. 2012;3(1):1413-1418.

9. Sugathan TN, Soman CR \& Sankaranarayanan KR. Behavioural risk factors for non communicable diseases among adults in Kerala, India. Indian J Med Res 2008; 127:555-563.

10. Pawar A T, Shinde P, John A. Study of prevalence of hypertension in rural population of Kerala. Journal of Evolution of Medical and Dental Sciences. 2012;1(6):123437.

11. Sebastian NM, Jesha MM, Haveri SP, Nath AS. Hypertension in Kerala: A study of prevalence, control, and knowledge among adults. Int J Med Sci Public Health 2016;5:2041-2046.

12. Kishor M Sochaliya1, Dipesh V Parmar2, Sudha B Yadav3. A study on Prevalence of Life-style diseases and its risk factors in urban area of Jamnagar city. National Journal of Community Medicine. 2012;3(4):595-600.

13. Meenakshi Bakshi Mehan, Somila Surabhi, Gautami T Solanki. Risk factor profile of non-communicable diseases among middle-income (18-65 years) free-living urban population of India 2006;26 (4):169-176.

14. Wilson C. "Eating, eating is always there": food, consumerism and cardiovascular disease. Some evidence from Kerala, south India. Anthropol Med. 2010;17:26175. [PubMed: 21153961] 